\title{
Distinct Mechanisms Govern the Dosage-Dependent and Developmentally Regulated Resistance Conferred by the Maize Hm2 Gene
}

\author{
Satya Chintamanani, ${ }^{1}$ Dilbag S. Multani, ${ }^{2}$ Holly Ruess, ${ }^{1}$ and Gurmukh S. Johal ${ }^{1}$ \\ ${ }^{1}$ Department of Botany and Plant Pathology, Purdue University, West Lafayette, IN 47907, U.S.A.; ${ }^{2}$ Pioneer Hi-Bred \\ International, Johnston, IA 50131, U.S.A.
}

Submitted 26 July 2007. Accepted 9 October 2007.

The maize $\mathrm{Hm} 2$ gene provides protection against the leaf spot and ear mold disease caused by Cochliobolus carbonum race 1 (CCR1). In this regard, it is similar to $\mathrm{Hml}$, the better-known disease resistance gene of the maize-CCR1 pathosystem. However, in contrast to $\mathrm{Hm} 1$, which provides completely dominant resistance at all stages of plant development, $\mathrm{Hm} 2$-conferred resistance is only partially dominant and becomes fully effective only at maturity. To investigate why $\mathrm{Hm} 2$ behaves in this manner, we cloned it on the basis of its homology to $\mathrm{Hm} 1$. As expected, $\mathrm{Hm} 2$ is a duplicate of $\mathrm{Hml}$, although the protein it encodes is grossly truncated compared with HM1. The efficacy of $\mathrm{Hm} 2$ in conferring resistance improves gradually over time, changing from having little or no impact in seedling tissues to providing complete immunity at anthesis. The developmentally specified phenotype of $\mathrm{Hm} 2$ is not dictated transcriptionally, because the expression level of the gene, whether occurring constitutively or undergoing substantial and transient induction in response to infection, does not change with plant age. In contrast, however, the $\mathrm{Hm} 2$ transcript is much more abundant in plants homozygous for this gene compared with plants that contain only one copy of the gene, suggesting a transcriptional basis for the dosage-dependent nature of $\mathrm{Hm} 2$. Thus, different mechanisms seem to underlie the developmentally programmed versus the partially dominant resistance phenotype of $\mathrm{Hm} 2$.

Additional keywords: adult plant resistance, HC-toxin, HCTR

Plant resistance to pathogens in many pathosystems is controlled by disease resistance (DR) genes (Ellis and Jones 2003; Johal et al. 1995; Staskawicz 2001). Variants of these DR genes exist naturally in plant populations where they are found segregating with the trait of resistance. Depending on how DR genes operate to confer resistance, they can be divided into two categories. In the first category are the so-called resistance $(R)$ genes that follow a gene-for-gene (GFG) paradigm to disrupt host-pathogen compatibility (Dangl and Jones 2001; Flor 1955). They do so by intercepting avirulence effectors of pathogens followed by triggering of a highly effective plant defense

Corresponding author: Gurmukh S. Johal; E-mail: gjohal@ purdue.edu

Present address of H. Ruess: Department of Horticulture, University of Wisconsin, Madison, WI 53706, U.S.A.

*The $\boldsymbol{e}$-Xtra logo stands for "electronic extra" and indicates that two supplemental figures are published online. response, the hypersensitive response (HR) (Innes 2004; Martin et al. 2003). The $R$ genes constitute the majority of DR genes in plants. They confer protection against all classes of phytopathogens, including fungi, oomycetes, bacteria, viruses, and nematodes, a common requirement of which is to invade biotrophically, at least during initial stages of colonization (Martin et al. 2003; Nimchuk et al. 2003).

In the second category are DR genes that operate on a nonGFG basis to directly interfere with the ability of a pathogen to colonize its host (Walton 1996; Wolpert et al. 2002). Only a few such DR genes have been identified thus far. A key representative among them is the maize $\mathrm{Hml}$ gene, which protects against a lethal leaf blight and ear rot disease caused by Cochliobolus carbonum race 1 (CCR1) (Johal and Briggs 1992). $\mathrm{Hml}$ is not only the first DR gene to be cloned in plants, it also is the only DR gene for which a biochemical mechanism has been elucidated thus far. $\mathrm{Hml}$ confers resistance against CCR1 by inactivating HC-toxin, a host-specific toxin absolutely needed by the pathogen to colonize maize (Meeley and Walton 1991; Meeley et al. 1992). This inactivation is mediated by an NADPH-dependent reductase, named HC-toxin reductase (HCTR), encoded by the Hml gene (Johal and Briggs 1992; Meeley et al. 1992).

In addition to $\mathrm{Hml}$, which is localized on the long arm of chromosome 1 (1L), a second gene exists on chromosome 9L that confers protection against CCR1 (Nelson and Ullstrup 1964). However, this gene, designated $H m 2$, behaves differently from $\mathrm{Hm} 1$. First, $\mathrm{Hm} 2$ exhibits incomplete dominance in conferring resistance, whereas $H m l$ is completely dominant. Second, in contrast to $\mathrm{Hml}$, which provides absolute protection in all parts of the plant at all stages of development, $\mathrm{Hm} 2$ confers effective resistance only at maturity (Nelson and Ullstrup 1964). As a result of the highly effective and dominant nature of $H m 1$, the presence of $H m 2$ remains masked in the maize germplasm and is revealed only when the wild-type $H m l$ is removed from the host background.

Many DR genes exist in plants whose resistance phenotype is programmed to integrate with plant development (Panter and Jones 2002; Whalen 2005). In these cases, full disease resistance is not exhibited until the host plant reaches a certain developmental stage. Resistance that is first apparent in older plants has been termed adult- or mature-plant or post-seedling resistance; in early literature, it frequently was referred to as field resistance (Dyck et al. 1966; Koh et al. 1987). The onset of adult plant resistance (APR) can vary and may be expressed gradually or abruptly. For example, the common wheat cv. Frontana has a post-seedling type of resistance to leaf rust that appears as early as the third-leaf stage, whereas resistance in 
cv. Exchange is not fully expressed until after the emergence of the flag leaf (Dyck et al. 1966). Although relatively rare, APR also sometimes can be conferred in a partially dominant manner. One recent example is provided by the RPP31 gene that protects Arabidopsis from downy mildew (McDowell et al. 2005). Three APR genes that are cloned thus far are $C f 9$, Mil, and Xa21 (Milligan et al. 1998; Parniske et al. 1997; Song et al. 1995). Because all of them confer protection on a GFG basis, it has been argued that there may be a link between the type of DR gene and its proclivity to become functionally dependent on plant development (Whalen 2005).

Despite the existence and the cloning of a number of developmentally regulated $R$ genes, our understanding of how these two traits become integrated remains unknown. In all cases studied in detail, the differential activity of the $R$ gene at the transcriptional level has not been found to underlie its differential phenotype (Whalen 2005). To address whether this is also the case with the maize $H m 2$ gene, we cloned and characterized its structural organization and transcriptional behavior. A partial sequence of the $h m 2$ allele of B73, which we have now demonstrated to be defective functionally, was reported before (Multani et al. 1998). In addition, this sequence was made available to other researchers interested in understanding the evolutionary dynamics of duplicated genes at the sequence level (Tiffin et al. 2004; Zhang et al. 2002).

\section{RESULTS}

\section{Cloning and confirmation of $\mathbf{H m} 2$.}

In our efforts to clone $h m 2$, we made use of an existing lambda genomic library of B73 that was used earlier to clone a number of other maize genes in our laboratory (Johal and Briggs 1992; Multani et al. 2003). Our cloning strategy was guided by the likelihood that $h m 2$ was a duplicate of $h m 1$. This reasoning stemmed from the hypothesis that modern maize, being derived from an ancient tetraploid, still contains a large number of duplicate genes (White and Doebley 1998). Indeed, $h m 1$ and $h m 2$ map to genomic locations that are related syntenically (Helentjaris et al. 1988). Additionally, we found a minor Hml-hybridizing restriction fragment on Southern blots exhibiting linkage to 9L markers (Multani et al. 1998), supporting our logic further.

To isolate clones harboring hm2, the B73 genomic library was first hybridized with a probe derived from the $3^{\prime}$ half of the $H m l$ cDNA that lacks the NADPH-binding domain common to many oxido-reductases (Johal and Briggs 1992). The clones that hybridized strongly to this probe were ignored, whereas the clones that exhibited low to intermediate signals were selected. These clones were then rehybridized with the $5^{\prime}$ half of the $H m l$ cDNA. This differential hybridization scheme allowed us to identify three overlapping clones that contained the entire gene. This gene was subcloned in two fragments into a pBluescript vector SK(+): a 1.6-kb BamHI fragment (pHM216) containing the $5^{\prime}$ end of the gene upstream of exon 2 , and a $1.5-\mathrm{kb}$ BamHI/SacI fragment (pHM215) containing the remainder of the gene.

To confirm that we had the correct gene, we tested the linkage of the cloned DNA with the resistance phenotype conferred by $H m 2$. An $H m 2$ backcross progeny that segregated 1:1 for partially resistant $(\mathrm{hm} 1 \mathrm{hm} 1 \mathrm{Hm} 2 \mathrm{hm} 2)$ versus susceptible $(\mathrm{hm} / \mathrm{hm} 1$ $h m 2 h m 2)$ plants was used for this purpose. No recombinants were found in 140 plants, placing our clone within 0.7 centimorgans of the $\mathrm{hm} 2$ locus. Examination of the recessive $\mathrm{hm} 2$ allele in a number of susceptible inbreds provided final confirmation that our clone originated from the $h m 2$ locus. These inbreds included Pr, the line on which the disease caused by CCR1 was first described in 1938 (Ullstrup 1941). Analysis based on Southern gel blots indicated the presence of an interstitial deletion within the $3^{\prime}$ end of the gene corresponding to our clone in many of the susceptible inbreds (Multani et al. 1998). Using polymerase chain reaction (PCR), we determined that this deletion is within exon 2 and exon 3 . To pinpoint the exact location of this deletion and also to decipher how much of the $h m 2$ gene it eliminated, we amplified the DNA flanking this deletion by thermal asymmetric interlaced (TAIL)-PCR from Pr as well as K61, another susceptible inbred (Nelson and Ullstrup 1964). The results revealed that the deletion is identical in both Pr and K61 and it eliminates the $h m 2$ gene downstream of intron 2. This deletion extends from nucleotide 420 (from the start codon of the gene) to beyond the confines of the $h m 2$ gene into an unknown genomic region. The finding that both Pr and K61 have inherited the same allele of $h m 2$ is intriguing, given that they were derived from maize lines considered to be largely unrelated (Multani et al. 1998).

\section{B73 has a defective allele of $\mathbf{h m} 2$.}

Although it was apparent from the Nelson and Ullstrup (1964) report that the hm2 alleles of both Pr and K61 were null, the status of the B73 allele of this gene was never assessed. To determine whether it was functional or not, a backcross population was generated between B73 and the recurrent parent Pr. This backcross population and the parental inbreds were inoculated with CCR1 at the V2 leaf stage (Anonymous 1993). Because B73 contains wild-type $\mathrm{Hml}$, half of the backcross progeny was completely resistant and, therefore, discarded. The susceptible plants were allowed to grow and were inoculated again at the V8 stage for second evaluation. All of these plants exhibited a completely susceptible phenotype, indicating that B73 does not have a functioning $\mathrm{Hm} 2$ gene.

To determine the molecular nature of the defect underlying the $h m 2$ allele of B73 (hm2-B73), we cloned the functional counterpart of this allele from a homozygous $\mathrm{Hm} 2$ line by high-fidelity PCR. The primers to amplify wild-type $\mathrm{Hm} 2$ were designed using the $h m 2-B 73$ genomic sequence as a guide. This allowed us to clone the entire coding region of the gene plus approximately $300 \mathrm{bp}$ of the promoter region.

Comparison of the hm2-B73 and functional (wild-type) $H m 2$ sequences revealed a number of polymorphisms. These included an 8-bp insertion in exon 1, a 6-bp insertion in the third intron, and various single-nucleotide changes in the $h m 2$ B73 allele relative to that of the functional $\mathrm{Hm} 2$ allele (Supplementary Figure S1). The 8-bp insertion in exon 1 of $\mathrm{hm} 2-\mathrm{B} 73$ appears to abolish the function of this allele; not only is the reading frame of the gene disrupted, but the insertion also introduces a stop codon shortly after the beginning of the gene (Supplementary Figure S2).

\section{$\mathrm{Hm} 2$ encodes a truncated version of $\mathrm{Hm} 1$.}

To determine the exact structure of the $h m 2$ gene and its encoded polypeptide, we cloned the Hm2 cDNA and compared its sequence with that of the $\mathrm{Hm} 2$ genomic region. This revealed the existence of four exons and three introns in the Hm2 gene (Fig. 1A). This contrasts with the structure of the $H m l$ gene, which has five exons and four introns (Johal and Briggs 1992). A close comparison of $\mathrm{Hm} 2$ with $\mathrm{Hm} \mathrm{l}$ revealed that the overall sequence and the exon/intron boundaries of the first four exons are conserved in the two genes. However, the sequence that constitutes exon 5 in $\mathrm{Hml}$ is altogether missing in $\mathrm{Hm} 2$. Also missing in $H m 2$, compared with $H m 1$, is most of intron 4, from beyond nucleotide 10 from its junction with exon 4 . The event that led to the deletion of the gene (beyond nucleotide 10 in intron 4) remains unknown, but it also caused two additional nucleotide changes at the exon 4/intron 4 boundary, changing

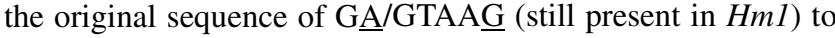


GL/GTAA $\underline{A}$ in Hm2. This sequence change abolished intron splicing at the exon 4/intron 4 junction and consequently brought a stop codon (TAA) in frame in $H m 2$. As a result, the predicted peptide of $\mathrm{Hm} 2$ is truncated by 52 amino acids (aa) compared with that of HM1. With the exception of these 52 aa, $\mathrm{Hml}$ and $\mathrm{Hm} 2$ are $89 \%$ identical at the amino acid level, confirming that these genes are duplicated (Fig. 1B). At the nucleotide level, they are approximately $82 \%$ identical. $H m 2$, like $H m 1$, harbors an NADPH binding site, needed for HCTR activity to inactivate HC-toxin by reductive detoxification (Johal and Briggs 1992; Meeley and Walton 1991).

In light of these findings, it is important to refer to an error made in various patents issued on Hm2 (Briggs et al. 2001, 2002). The gene that these patents have listed to be the wildtype form of $\mathrm{Hm} 2$ is, in fact, a different gene, which we have now renamed hml-likel ( $h m l l)$ because of its location on $7 \mathrm{~S}$ (unpublished data). This genomic region has never been shown to be associated with resistance to CCR1; therefore, it is unlikely that $h m l l$ encodes an HCTR.

\section{Developmental profile of $\mathrm{Hm} \mathbf{2}$-mediated resistance.}

In the article that reported the discovery of $\mathrm{Hm} 2$, maize plants were inoculated only twice, first at the seedling stage and then again approximately 3 weeks later (Nelson and Ullstrup 1964). Although this inoculation strategy revealed the APR conferred by $H m 2$, it did not disclose whether the onset of the Hm2 phenotype was progressive or abrupt. To generate a detailed developmental profile of $H m 2$, we inoculated plants homozygous (Hm2Hm2) and heterozygous $(\mathrm{Hm} 2 \mathrm{hm} 2)$ for this gene at weekly intervals with CCR 1 from week 2 to week 10 after planting. Infection phenotypes of these plants were compared with control plants that either lacked both $h m 1$ and $h m 2$ or contained at least one functional copy of the $\mathrm{Hml}$ gene ( $\mathrm{Hml}$ - $\mathrm{hm} 2 \mathrm{hm} 2$ ). A disease-rating scale of 1 to 10 , where 10 is highly susceptible and 1 completely resistant, was used (Nelson and Ullstrup 1964) (Fig. 2). Control plants that lacked both resistance genes $(\mathrm{hm} / \mathrm{hm} 2)$ were scored 10 on this scale regardless of age. This rating was based on both the morphology of lesions (having concentric rings with gray margins) and their tendency to expand continually, causing the leaf to collapse or blight. Control plants containing $\mathrm{Hml}$ had a rating of 1 throughout, because they developed only minute chlorotic flecks in response to infection (Fig. 2A)

In contrast, the resistance-conferring ability of the Hm2 gene increased gradually over time as the plant developed. At the seedling stage, $\mathrm{Hm} 2$ afforded little or no resistance and plants had a rating of 8 to 9 (Fig. 2B). First indications of resistance of $\mathrm{Hm} 2 \mathrm{Hm} 2$ plants became apparent at approximately week 4 after planting, when the average disease rating dropped to approximately 6 . This rating continued to drop progressively as plants aged, and they became essentially immune to CCR1 by the time they reached anthesis (Fig. 3).

The effect of gene dosage of $\mathrm{Hm} 2$ on CCR1 resistance also was apparent throughout our study. Plants heterozygous for $H m 2$ (Hm2hm2) were markedly more susceptible than the $\mathrm{Hm} 2 \mathrm{Hm} 2$ homozygotes, and this difference was clearly noticeable at most stages of growth (Figs. 2 and 3). Still, although the plants lacking both $\mathrm{hm} 1$ and $\mathrm{hm} 2$ always died, plants heterozygous for $\mathrm{Hm} 2$ almost always survived, especially if infection was delayed to 4 weeks after planting or later (Fig. 4).

Transcriptional profile of $\mathbf{H m} \mathbf{2}$ during plant development.

The Hm2 gene is expressed at very low levels, and this prevented us from using Northern blots to examine the expression of this gene in relation to plant development. Therefore, a semiquantitative reverse transcription (RT)-PCR assay was

A

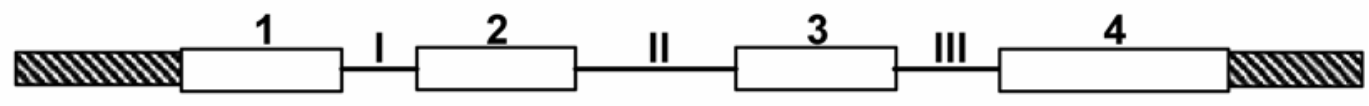

B

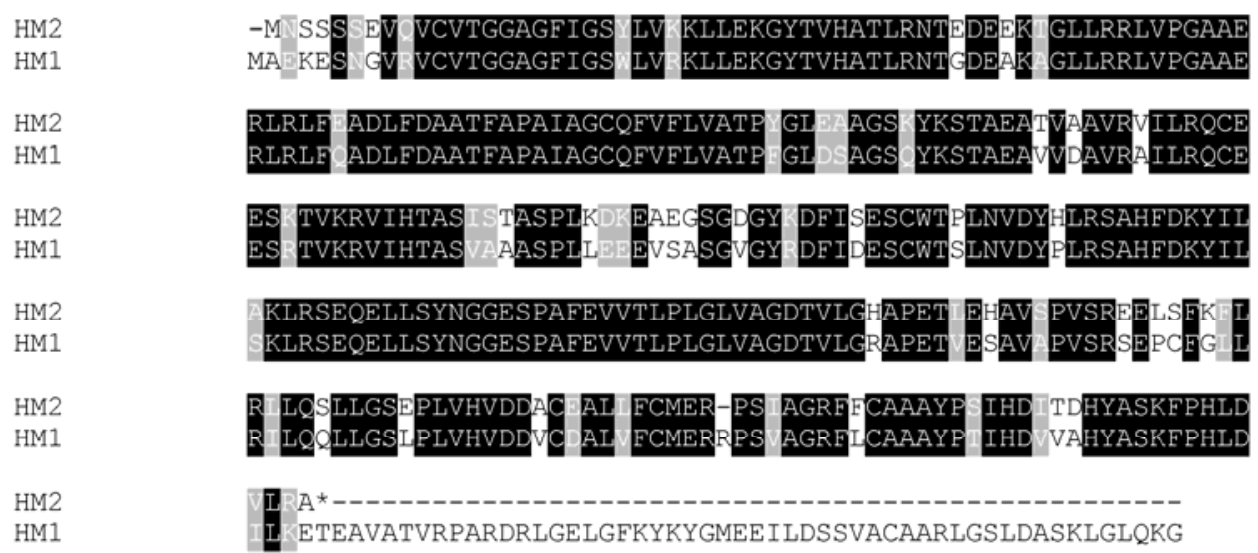

Fig. 1. $\mathrm{Hm} 2$ is a duplicate of the $\mathrm{Hm} 1$ gene. A, Structural representation of the $\mathrm{Hm} 2$ gene. Boxes represent the four exons and the connecting lines represent three introns. B, Alignment of the predictable peptides of $\mathrm{Hm} 1$ and $\mathrm{Hm} 2$. The homologous amino acids are in black and the conserved amino acid groups are in gray. Dashes represent the missing residues. 
used to look at the expression level of $\mathrm{Hm} 2$ at different stages of development in both homozygous and heterozygous plants. So low is the transcriptional activity of the $H m 2$ gene that it took $200 \mathrm{ng}$ of total RNA for first-strand synthesis and still at least 30 cycles of PCR to amplify $\mathrm{Hm} 2$ with gene specific primers.

The expression level of $\mathrm{Hm} 2$ essentially remained the same as the plants progressed from the seedling to the adult stage (Fig. 5A). No correlation could be detected between the expression level of $\mathrm{Hm} 2$ and its ability to confer developmentally specified resistance, whether in homozygous condition or heterozygous condition. In contrast, the expression levels of $\mathrm{Hm} 2$ were clearly different when plants containing one or two copies of the Hm2 gene were compared. The level of the Hm2 transcript was markedly higher in homozygous plants at all stages of development compared with heterozygous plants (Fig. 5A). Together, these results indicate that, although the dosagedependent nature of $\mathrm{Hm} 2$ resistance is dictated at the level of transcription, its developmentally specified phenotype is not. Thus, some other mechanism may exist that allows $h m 2$ to confer resistance to CCR1 in adult tissues but not in seedling tissues (Fig. 2B).

\section{$\mathrm{Hm} 2$ is stress inducible.}

We recently found that the $\mathrm{Hml}$ gene undergoes a marked and transient induction in response to infection by CCR1 (S. Chintamanani and G. S. Johal unpublished data). To determine whether $H m 2$ also exhibits such an induction in response to CCR1, its expression was monitored in response to inoculation with the pathogen. There was a significant (at least fivefold) increase in the level of the Hm2 transcript that peaked from 24 to $48 \mathrm{~h}$ after inoculation before declining to normal levels (Fig. $5 \mathrm{~B})$. Whether the plants were inoculated with virulent (HCtoxin-producing) or avirulent (HC-toxin-nonproducing) isolates of the pathogen, similar enhancement and induction kinetics of the $\mathrm{Hm} 2$ transcript were observed (Fig. 5B), suggesting that HCtoxin is not the factor mediating infection-inducible upregulation of $H m 2$. To determine whether the signal to induce $H m 2$ may be provided by physical injury associated with fungal ingress, $\mathrm{Hm} 2$ plants were wounded and sampled for RNA at different time points. Again, $\mathrm{Hm} 2$ was found to be induced markedly in a transient manner, reaching peak levels at $16 \mathrm{~h}$ after wounding (haw) and decreasing to basal levels by 32 haw (Fig. 5C). The levels and kinetics of $\mathrm{Hm} 2$ induction were not impacted by the developmental maturity of maize plants (data not shown). These re-

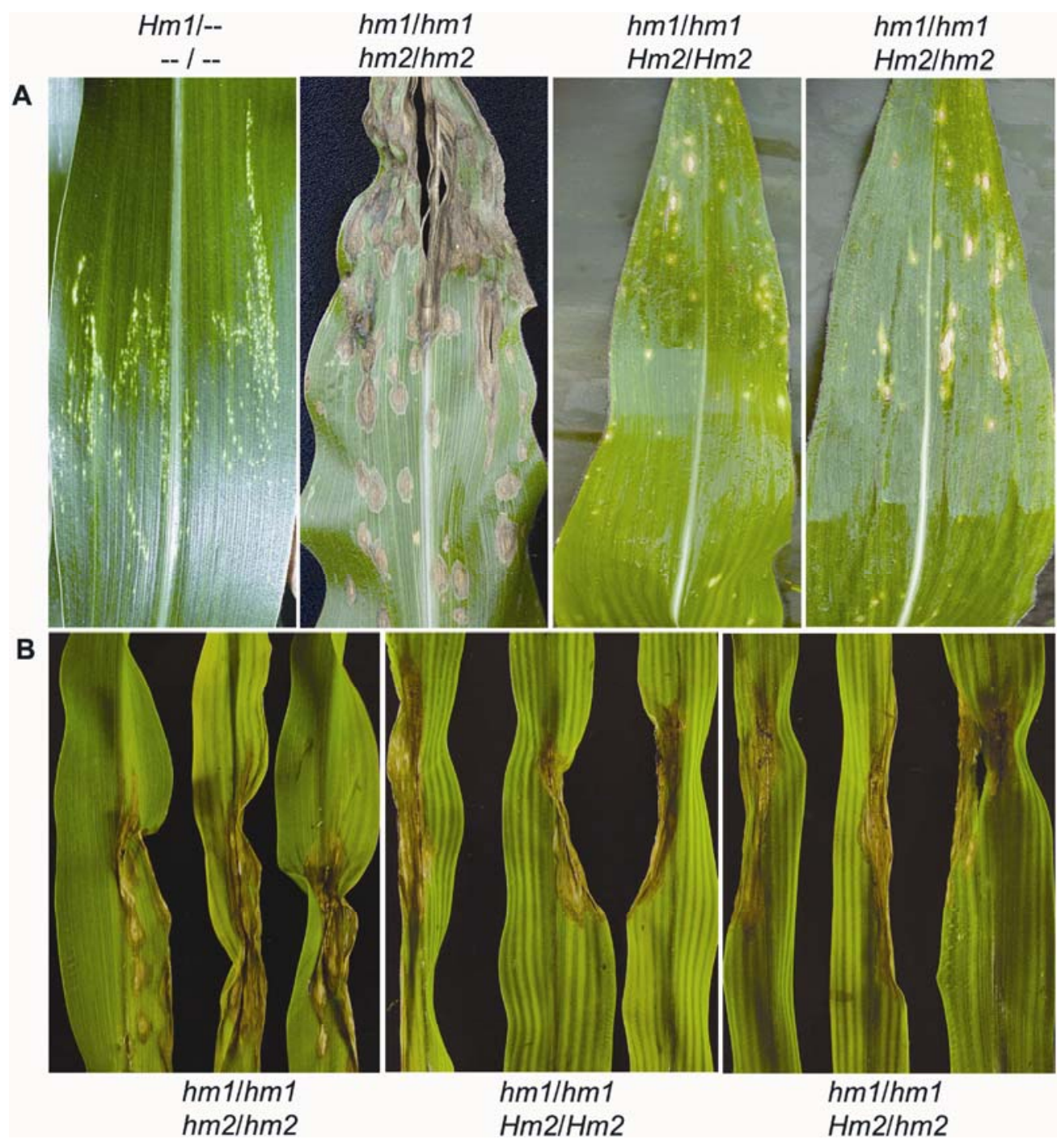

Fig. 2. A, Different levels of resistance or susceptibility in maize to Cochliobolus carbonum race 1 (CCR1). Seven-week-old maize plants homozygous or heterozygous for $\mathrm{Hm} 2$ were whorl inoculated with CCR1. The controls were $\mathrm{hm} 1 \mathrm{hm} 1 \mathrm{hm} 2 \mathrm{hm} 2$ (lacking both $\mathrm{hm} 1$ and $\mathrm{hm} 2$ and, therefore, completely susceptible) and $\mathrm{Hm} 1 \mathrm{hm} 1 \mathrm{hm} 2 \mathrm{hm} 2$ (containing one allele of the wild-type $\mathrm{Hm} 1$ and, therefore, completely resistant). Images were captured after 15 days of inoculation. Identical infection phenotypes were observed in three independent experiments. B, Lack of resistance conferred by $\mathrm{Hm} 2$ in seedling leaves. Two-weekold maize seedlings containing different doses of the $\mathrm{Hm} 2$ gene were whorl inoculated with CCR1 and photographed after 7 days. 
sults eliminated the possibility that the differential induction of $H m 2$ at different developmental stages was responsible for the age-related resistance phenotype of $\mathrm{Hm} 2$.

\section{DISCUSSION}

The findings presented here confirm, extend, and reveal a number of features of the maize $\mathrm{Hm} 2$ gene and the resistance that it imparts to CCR1. First, Hm2 is clearly a duplicate of $H m 1$. Their residence on seemingly homologous chromosomes of maize, which is thought to be derived from an ancient tetraploid (Helentjaris et al. 1988), indicates that these two genes are ancestrally related. Interestingly, however, $\mathrm{Hm} 2$ encodes a product that is 52 aa shorter than that of HM1, which represents the original form because the barley and rice homologs of these genes are of the same size as the $\mathrm{Hml}$ gene (Han

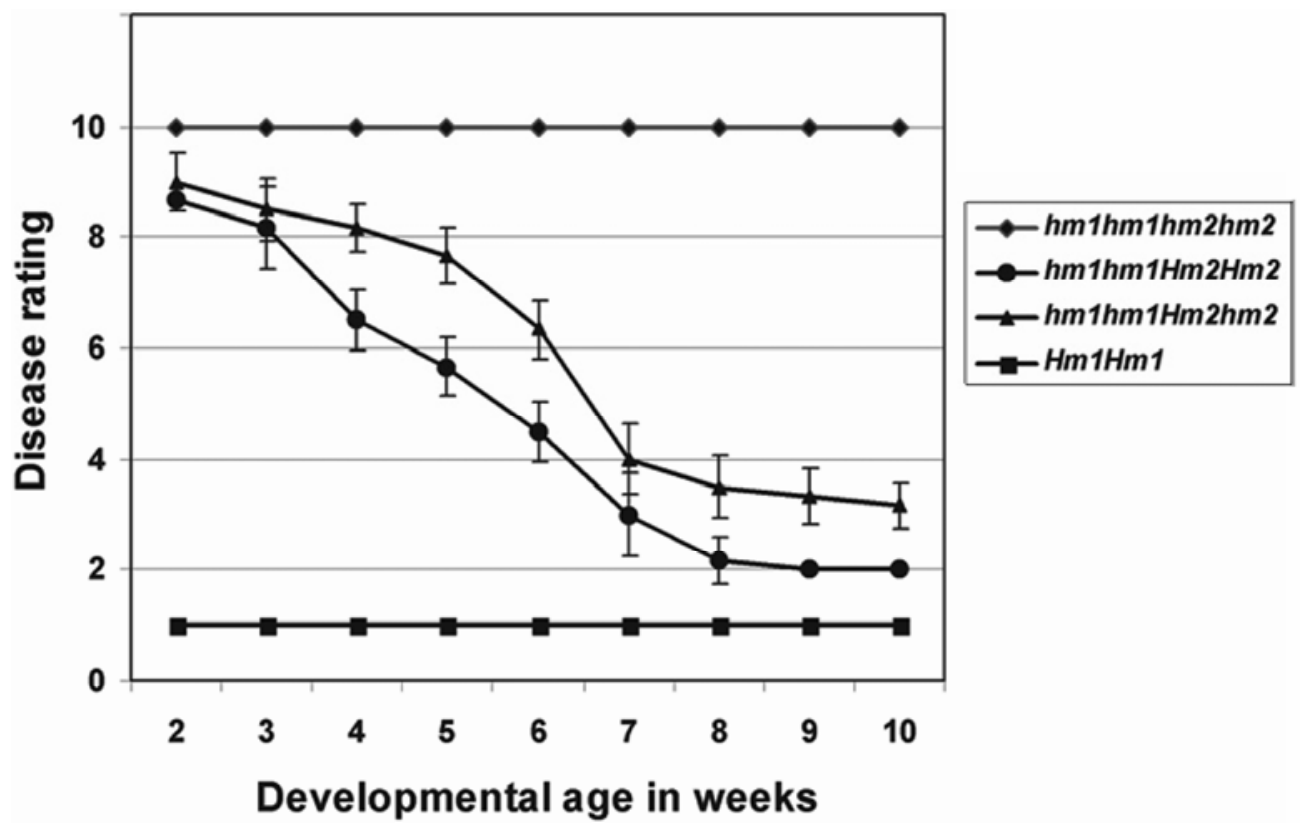

Fig. 3. Adult plant resistance conferred by $\mathrm{Hm} 2$ develops gradually over time. Disease ratings of maize plants homozygous $(\mathrm{Hm} 2 \mathrm{Hm} 2)$ or heterozygous $(\mathrm{Hm} 2 \mathrm{Hm} 2)$ for $\mathrm{Hm} 2$ at different stages of development. The controls were $\mathrm{hm} 1 \mathrm{hm} 1 \mathrm{hm} 2 \mathrm{hm} 2$ (lacking both $\mathrm{hm} 1$ and $\mathrm{hm} 2$ and, therefore, completely susceptible) and $\mathrm{Hm} 1 \mathrm{hm} 1 \mathrm{hm} 2 \mathrm{hm} 2$ (containing one allele of the wild-type $\mathrm{Hml}$ and, therefore, completely resistant). Plants were whorl inoculated with approximately 50,000 spores of Cochliobolus carbonum race 1 (CCR1) and disease assessments were made 10 days following inoculation using a 1-to-10 disease rating scale. A set of 10 previously uninfected plants were used for CCR1 inoculations every week.
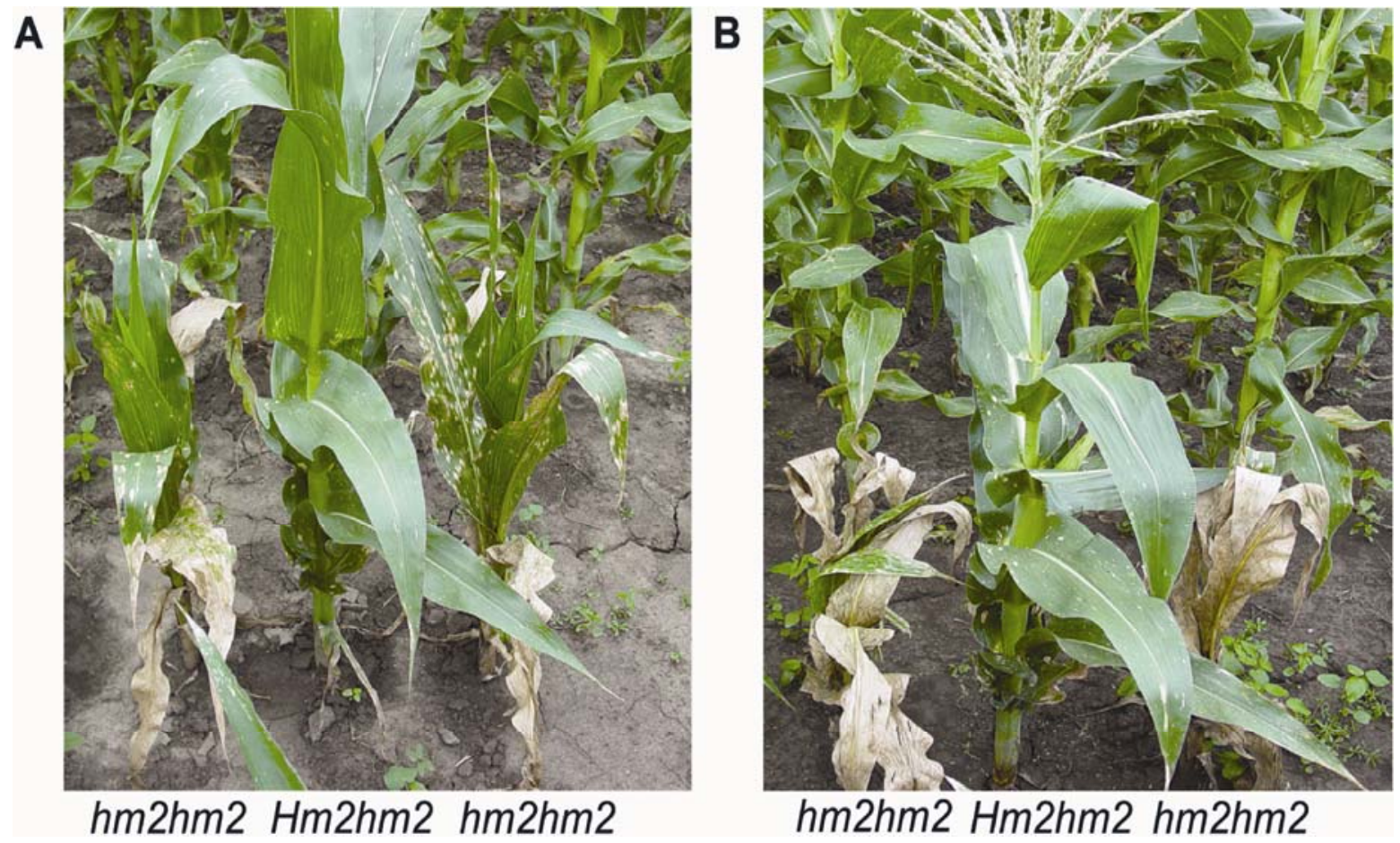

Fig. 4. A single copy of $\mathrm{Hm} 2$ is sufficient to prevent Cochliobolus carbonum race 1 from killing maize. Plants containing a single copy (the middle plant) or no copy (side plants) of the $\mathrm{Hm} 2$ gene were inoculated on week 6 after planting. Pictures are of the same plants taken at $\mathbf{A}$, week 10 and $\mathbf{B}$, week 13 after planting. 
et al. 1997, Hayashi et al. 2005) The truncation of the last 52 aa in HM2 is the result a deletion of the entire exon 5 of $\mathrm{Hm} 1$. It is intriguing that, despite this dramatic truncation, the $\mathrm{Hm} 2$ protein has not lost its resistance function appreciably, at least at maturity, although it remains possible that this truncation is the reason why $\mathrm{Hm} 2$ behaves in an atypical fashion in conferring resistance.

Second, as was reported previously (Nelson and Ullstrup 1964), the protection provided by $H m 2$ against CCR 1 is developmentally programmed. This resistance phenotype manifests gradually over time as the plant ages, changing from having a negligible effect on disease at the seedling stage to being highly efficacious at maturity. Why $\mathrm{Hm} 2$ resistance behaves this way remains an open question. However, it does not seem to be dictated by the transcriptional activity of $H m 2$, because both its constitutive and infection-inducible levels of expression remain unaltered during the course of plant development. Induction of $\mathrm{Hm} 2$ is transient and occurs not only in response to infection but also to wounding, suggesting that it is not some specific feature of the pathogen but, rather, physical stress associated with fungal ingress that enhances the transcriptional activity of $\mathrm{Hm} 2$. The detailed nature of this stress and the signaling pathways that it may involve to induce $\mathrm{Hm} 2$ remain unaddressed.

Third, the protection provided by $\mathrm{Hm} 2$ is sensitive to genedosage effect; two copies of the gene confer a higher level of resistance than a single copy during most stages of plant development. Not too surprisingly, this dosage-dependent behavior of Hm2 appears to be regulated transcriptionally; homozygous plants have much higher levels of the Hm2 transcript compared

A

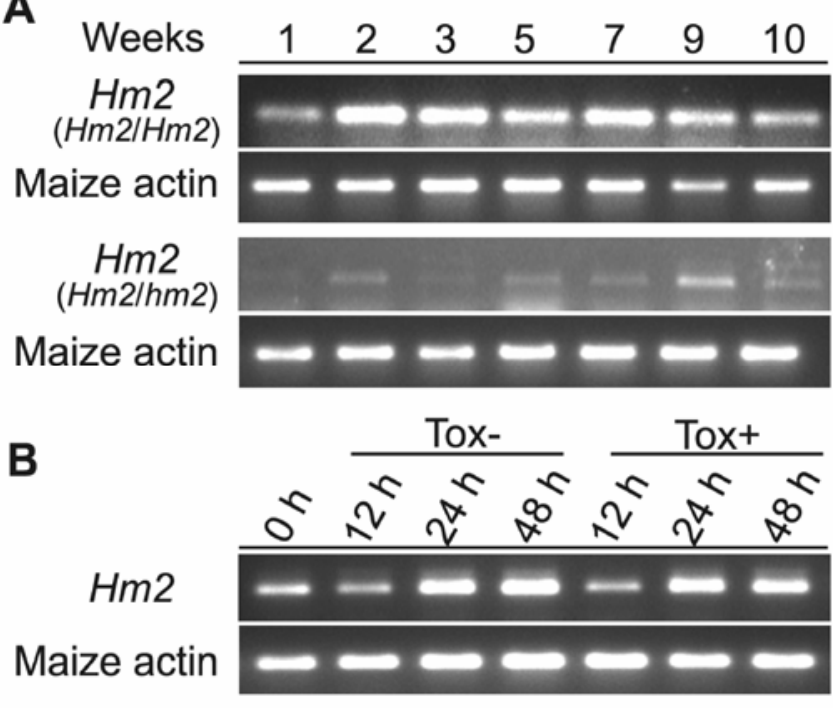

C

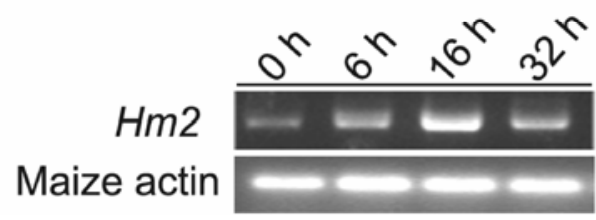

Fig. 5. Expression analysis of Hm2. A, Reverse-transcription polymerase chain reaction (RT-PCR) amplification of the $\mathrm{Hm} 2$ transcripts from $\mathrm{Hm} 2$ homozygous (upper panel) and Hm2 heterozygous (lower panel) plants at different weeks after planting. The maize actin gene was used as a control to ensure equal amplification and loading of PCR products. $\mathbf{B}$, Induction of the Hm2 gene following infection with the Tox+ and Tox- strains of Cochliobolus carbonum race 1. C, Induction of $\mathrm{Hm} 2$ in response to physical wounding. All RT-PCR experiments were repeated three times with similar results. with those of heterozygous plants. Thus, distinct mechanisms appear to be responsible for the developmental- versus dosagedependent behaviors of resistance encoded by $\mathrm{Hm} 2$.

The Hm2 gene provides yet another example of a plant disease resistance gene whose developmentally programmed phenotype is independent of transcriptional activity. Other genes that have been shown to defy this expectation include tomato $C f 9 b$ (Panter et al. 2002), which confers resistance to Cladosporium fulvum; tomato $\mathrm{Mil}$, which confers resistance to aphid (Goggin et al. 2004); and the rice Xa21 gene, which confers resistance against the bacterial blight pathogen (Century et al. 1999). All of these genes belong to the gene-for-gene class, and they unleash a resistance response by recognizing avirulence effectors of their respective pathogens. In contrast, $\mathrm{Hm} 2$ is expected to confer resistance directly. Being a duplicate of $\mathrm{Hml}$, it is expected to encode an enzyme (HCTR) whose function is to degrade HC-toxin, a key virulence factor of CCR1 (Johal and Briggs 1992). Therefore, inclusion of Hm2 in this list with $C f 9 b, M i 1.2$, and $X a 21$ suggests that whether or not a DR gene becomes integrated with plant development depends not on its modus operandi but on some elusive characteristic. One feature that seems common to all of these developmentally regulated genes is that they are normally expressed at very low levels (Whalen 2005).

Despite the prevalence of developmentally programmed resistance in plants, its mechanistic basis remains an enigma. One possibility is that it is brought about by the action of an interfering RNA, such as miRNA (Chuck et al. 2007). However, most RNA interference (RNAi)-based mechanisms in plants regulate the level of the target transcript, causing it to degrade in a developmentally specified fashion. This does not seem to be the case with the Hm2 transcript, because its abundance remains unaltered during development. Thus, if an RNAi-mediated mechanism is involved in the regulation of developmental competence of $\mathrm{Hm} 2$, it must work at the level of translation, as do many miRNAs in animals (Bushati and Cohen 2007). Alternatively, the mechanism is something different that affects HM2 post-translationally to regulate its stability or enzymatic (HCTR) activity. Whatever the nature this mechanism, it appears to impact Hm2 directly because plants that are devoid of both $h m 1$ and $h m 2$ remain completely susceptible throughout their life, and plants that contain $\mathrm{Hml}$ remain resistant throughout.

One way to address the mechanism underlying the developmental regulation of $\mathrm{Hm} 2$ would be to use an $\mathrm{Hm} 2$-specific antibody to monitor HM2 levels at different stages of development. This antibody is not available yet but is under development. Assaying directly for the HCTR activity is an additional option (Meeley and Walton 1991; Meeley et al. 1992). In fact, we have used this assay to show that, despite the transcriptional activity of the Hm2 gene, no HCTR activity was present in maize seedlings (S. Chintamanani and G. S. Johal, unpublished data). However, there are two problems with the HCTR assay. First, it does not indicate whether the failure is due to the lack of the HCTR activity or the absence of the HM2 protein altogether. Second, the utility of the HCTR assay is limited to the etiolated seedling tissue, because it does not work reliably with tissues that are old or green (Meeley and Walton 1991; Meeley et al. 1992). Efforts are being made to address these problems.

Apparently, Hm2 is not the only gene in the maize-CCR 1 pathosystem that provides protection in a developmentally regulated manner. Two additional alleles have been reported at the $h m 1$ locus whose ability to confer resistance against CCR1 is also developmentally regulated (Nelson and Ullstrup 1964). One of them is $\mathrm{HmlA}$ which, like $\mathrm{Hm} 2$, affords little protection at the seedling stage but becomes highly effective after anthesis. In contrast, $\mathrm{HmlB}$ 's ability to confer resistance decreases after anthesis (Nelson and Ullstrup 1964). However, 
this loss of efficacy occurs only if $H m l B$ is in heterozygous condition, because plants homozygous for this allele remain resistant throughout the life of the plant. On the other hand, plants containing a single copy of $\mathrm{HmlB}$ are completely resistant as seedlings but become moderately susceptible following reproduction (Nelson and Ullstrup 1964). The existence of so many developmentally regulated and contrasting DR genes in the maize-CCR1 pathosystem is intriguing, and it also provides an excellent opportunity to unlock how DR genes become tangled with plant development.

Given that most duplicated genes of the originally tetraploid maize genome have been lost over evolutionary time (White and Doebley 1998), the persistence of the Hm2 gene in the maize genome is enigmatic. There is seemingly no reason for $H m 2$ to have been maintained by selection, considering that its progenitor, $\mathrm{Hml}$, is so effective and prevalent in the maize germplasm (Multani et. al. 1997). Even more puzzling is the finding that, in Teosinte, the wild progenitor of maize, the sequence of $\mathrm{hm} 2$ appears to be under some sort of positive selection (Zhang et al. 2002). For instance, at the sequence level, although $\mathrm{hml}$ is among the most diverse genes in Teosinte, $h m 2$ is among the least diverse. In fact, population genetics studies of sequence diversity have indicated the involvement of a recent selective sweep for the $\mathrm{hm} 2$ sequence (its resistance function was not addressed in these studies) in two of the three Teosintes examined (Tiffin et al. 2004). What could be the forces responsible for the survival and specific selection of $h m 2$ in the maize genome? One possibility is that it is probably not the $\mathrm{Hml}$ allele but $\mathrm{HmlB}$ that is present more widely in the Teosinte germplasm. When existing in a homozygous condition, as it does in some maize inbreds, $\mathrm{HmlB}$ confers complete protection throughout plant development (Nelson and Ullstrup 1964). However, in wild species of Zea, which is largely crosspollinating, $\mathrm{Hm} / \mathrm{B}$ can exist in a heterozygous condition with the loss-of-function alleles of $h m l$, thereby leaving plants vulnerable to infection by CCR1. To have complete protection both during early and later stages, plants would need $H m 2$ as well. Efforts are in progress to assess the genetic and molecular nature of these genes in Teosinte.

\section{MATERIALS AND METHODS}

\section{Plant materials.}

Seed of plants containing two or none copies of the functional $\mathrm{Hm} 2$ gene were obtained from the Maize Genetics Cooperation Stock Center, Urbana-Champaign, IL, U.S.A. The catalog numbers of these stocks are $114 \mathrm{~F}(\mathrm{hm} / \mathrm{hm} 1 \mathrm{Hm} 2 \mathrm{Hm} 2)$ and $114 \mathrm{G}$ ( hm $1 \mathrm{hm} 1 \mathrm{hm} 2 \mathrm{hm} 2$ ). Plants containing a single copy of the Hm2 gene $(\mathrm{hm} 1 \mathrm{hm} 1 \mathrm{Hm} 2 \mathrm{hm} 2)$ were generated by fertilizing $114 \mathrm{~F}$ ears with $114 \mathrm{G}$ pollen. These F1 hybrids were crossed with $114 \mathrm{G}$ pollen to generate the backcross progeny that segregated 1:1 for $H m 2$-mediated resistance. The backcross progeny used to assess the status of the B73 $\mathrm{hm} 2$ allele was prepared by crossing this inbred with Pr, the recurrent parent.

\section{Pathogen growth and inoculations.}

The protocols used to culture CCR1 on carrot juice agar and to prepare inoculum were as described before (Johal and Briggs 1992). For most experiments, plants were inoculated by dropping spore suspensions of CCR1 (50,000 conidia/inoculation) in leaf whorls. For experiments conducted to determine the induction of $\mathrm{Hm} 2$ in response to infection, plants were heavily misted with CCR1 spore suspensions at a concentration of $5 \times$ $10^{5}$ spores $/ \mathrm{ml}$ and then incubated in humid chambers for $24 \mathrm{~h}$. To look at the developmental profile of $\mathrm{Hm} 2$-mediated resistance, 10 maize plants of each genotype were inoculated fresh each time. For wounding, maize leaves were pinched with a hemostat several times (Nemchenko et al. 2006). Digital photographs of infected plants were taken with a Sony MVCCD400 camera.

\section{Cloning of $\mathrm{Hm} 2$.}

Genomic clones of $h m 2$ were isolated from a lambda B73 library as described earlier for $\mathrm{hml}$ (Johal and Briggs 1992; Multani et al. 2003). The functional Hm2 allele was cloned from the $H m 2$ tester $(114 \mathrm{~F})$ as overlapping PCR fragments by using the following primer combinations: 5'-TCAACTACAAC CCTCAGCCTGT-3' and 5'-ACTGCTGTTCATGGTCTTCTC CGT-3' to amplify the $5^{\prime}$ end of the gene; $5^{\prime}$-AGTGCCCTAGT CCATCGAGTAGCA-3' and 5'-TTTGTACCCATCGCCGGA ACC-3' to amplify the part of the $\mathrm{Hm} 2$ gene between exon 1 and exon 3; 5'-ACATCGCACTTTCGTCCCTTGTCT-3' and 5'-TAGTGGTCCGTGATGTCGTGGATG-3' to amplify intron 2 through intron 4; and 5'-CCTTCGCAGCGCACACTTCGA$3^{\prime}$ and 5'-TTACGCTCTGAGGACGTCGAGG-3' to amplify from exon 3 to the $3^{\prime}$ end of the gene. PCR fragments thus amplified were subcloned into the pGem-T Easy Vector system (Invitrogen, Carlsbad, CA, U.S.A.) and DNA and were sequenced at the Purdue Genomic Facility. To ensure that the correct sequence of the gene was obtained, each PCR reaction was done three times.

\section{Molecular analyses.}

Total RNA from maize leaves was extracted using TRIZOL (Invitrogen) and was treated with RNase-free DNase I (Promega Corp., Madison, WI, U.S.A.). For semiquantitative RT-PCR, 200 ng of total RNA was reverse transcribed to generate first-strand cDNA using a one-step RT-PCR kit (Qiagen, Valencia, CA, U.S.A.). The primers Hm2F (5'-CCTTCGCAG CGCACACTTCGA-3') and Hm2R (5'-TAGTGGTCCGTGAT GTCGTGGATG-3') were used to amplify the maize $H m 2$ transcript. The primers ActinF (5'-GCATCCTGACACTGAAG TAC-3') and ActinR (5'-GATAGCAACATACATTGCTGG-3') were used to amplify the maize Actin gene transcript as a control. Reverse transcription was performed at $50^{\circ} \mathrm{C}$ for $30 \mathrm{~min}$, followed by activation of DNA polymerase at $95^{\circ} \mathrm{C}$ for $15 \mathrm{~min}$. PCR reactions had the following thermal profile: denaturation at $94^{\circ} \mathrm{C}$ for $1 \mathrm{~min}$, annealing at $60^{\circ} \mathrm{C}$ for $1 \mathrm{~min}$, extension at $72^{\circ} \mathrm{C}$ for $1 \mathrm{~min}$, and a terminal extension step for $10 \mathrm{~min}$. Thirty-two cycles of PCR were used to examine the developmental profile of the $\mathrm{Hm} 2$ gene as well as its induction kinetics following CCR1 infection. However, only 30 PCR cycles were used to amplify the Hm2 transcript following wounding. The control gene (actin) was run for 28 cycles in all experiments. TAIL-PCR was performed as described previously (Settles et al., 2004) using the gene-specific primer 5'-AGTGCCCTAGT CCATCGAGTAGCA-3'.

\section{ACKNOWLEDGMENTS}

We thank L. Dunkle, C. Woloshuk, and P. Balint-Kurti for cortically reading the manuscript and providing comments. This work was made possible in part by start-up funds from Purdue University and in-part by a National Science Foundation grant to G. S. Johal.

\section{LITERATURE CITED}

Anonymous. 1993. How a Corn Plant Develops. Iowa State University, Ames, U.S.A

Botella, M. A., Parker, J. E., Frost, L. N., Bittner-Eddy, P. D., Beynon, J. L., Daniels, M. J., Holub, E. B., and Jones, J. D. 1998. Three genes of the Arabidopsis RPP1 complex resistance locus recognize distinct Peronospora parasitica avirulence determinants. Plant Cell 10:1847-1860.

Briggs, S. P., Johal, G. S., , and Multani, D. S. 2001. Hm2 cDNA from Maize Encoding Disease Resistance Polypeptide. Pioneer Hi-Bred International, Inc., Johnston, IA, U.S.A. 
Briggs, S. P., Johal, G. S., , and Multani, D. S. 2002. Hm2 cDNA and Related Polypeptide. Pioneer Hi-Bred International, Inc., Johnston, IA, U.S.A.

Bushati, N., and Cohen, S. M. 2007. microRNA functions. Annu. Rev. Cell. Dev. Biol. 23:175-205.

Century, K. S., Lagman, R. A., Adkisson, M., Morlan, J., Tobias, R., Schwartz, K., Smith, A., Love, J., Ronald, P. C., and Whalen, M. C. 1999. Short communication: Developmental control of Xa21-mediated disease resistance in rice. Plant J. 20:231-236.

Chuck, G., Cigan, A. M., Saeteurn, K., and Hake, S. 2007. The heterochronic maize mutant Corngrass 1 results from overexpression of a tandem microRNA. Nat. Genet. 39:544-549.

Dangl, J. L., and Jones, J. D. 2001. Plant pathogens and integrated defence responses to infection. Nature 411:826-833.

Dyck, P., Samborski, D. J., and Anderson, R. G. 1966. Inheritance of adult-plant leaf rust resistance derived from the common wheat varieties Exchange and Frontana. Can. J. Genet. Cytol. 8:665-671.

Ellis, J., and Jones, D. A. 2003. Plant disease resistance genes. Pages 2745 in: Infectious Disease: Innate Immunity. J. A.. Hoffmann and R. A. Ezecowitz, eds. Humana Press, Totowa, NJ, U.S.A.

Flor, H. 1955. Host-parasite interactions in flax-its genetics and other implications. Phytopathology 45:680-685.

Goggin, F. L., Shah, G., Williamson, V. M., and Ullman, D. E. 2004. Developmental regulation of $M i$-mediated aphid resistance is independent of Mi-1.2 transcript levels. Mol. Plant-Microbe Interact. 17:532-536.

Han, F., Kleinhofs, A., Kilian, A., and Ullrich, S. E. 1997. Cloning and mapping of a putative barley NADPH-dependent HC-toxin reductase. Mol. Plant-Microbe Interact. 10:234-239.

Hayashi, M., Takahashi, H., Tamura, K., Huang, J., Yu, L. H., KawaiYamada, M., Tezuka T., and Uchimiya, H.2005. Enhanced dihydroflavonol-4-reductase activity and NAD homeostasis leading to cell death tolerance in transgenic rice. Proc. Natl. Acad. Sci. U.S.A. 102:7020-7025.

Helentjaris, T., Weber, D., and Wright, S. 1988. Identification of the genomic locations of duplicate nucleotide sequences in maize by analysis of restriction fragment length polymorphisms. Genetics 118:353-363.

Innes, R. W. 2004. Guarding the goods: New insights into the central alarm system of plants. Plant Physiol. 135:695-701.

Johal, G., Gray, J., Gruis, D., and Briggs, S. 1995. Convergent insights into mechanisms determining disease and resistance responses in plantfungal interactions. Can. J. Bot. 73S:468-474.

Johal, G. S., and Briggs, S. P. 1992. Reductase activity encoded by the HM1 disease resistance gene in maize. Science 258:985-987.

Koh, Y. J., Hwang, B. K., and Chung, H. S. 1987. Adult-plant resistance of rice to leaf blast. Phytopathology 77:232-236.

Martin, G. B., Bogdanove, A. J., and Sessa, G. 2003. Understanding the functions of plant disease resistance proteins. Annu. Rev. Plant Biol. 54:23-61.

McDowell, J. C., Williams, S. G., Funderburg, N. T., Eulgem, T., and Dangl, J. L. 2005. Genetic analysis of developmentally regulated resistance to downy mildew (Hyalopernospora parasitica) in Arabidopsis thaliana. Mol. Plant-Microbe Interact. 18:1226-1234.

Meeley, R. B., and Walton, J. D. 1991. Enzymatic detoxification of HCtoxin, the host-selective cyclic peptide from Cochliobolus carbonum. Plant Physiol. 97:1080-1086.

Meeley, R. B., Johal, G. S., Briggs, S. P., and Walton, J. D. 1992. A biochemical phenotype for a disease resistance gene of maize. Plant Cell 4:71-77.
Milligan, S. B., Bodeau, J., Yaghoobi, J., Kaloshian, I., Zabel, P., and Williamson, V. M. 1998. The root knot nematode resistance gene $M i$ from tomato is a member of the leucine zipper, nucleotide binding, leucine-rich repeat family of plant genes. Plant Cell 10:1307-1319.

Multani, D. S., Meeley, R. B., Paterson, A. H., Gray, J., Briggs, S. P., and Johal, G. S. 1998. Plant-pathogen microevolution: Molecular basis for the origin of a fungal disease in maize. Proc. Natl. Acad. Sci. U.S.A. 95:1686-1691.

Multani, D. S., Briggs, S. P., Chamberlin, M. A., Blakeslee, J. J., Murphy, A. S., and Johal, G. S. 2003. Loss of an MDR transporter in compact stalks of maize $b r 2$ and sorghum $d w 3$ mutants. Science 302:81-84.

Nelson, O. E., and Ullstrup, A. J. 1964. Resistance to leaf spot in maize. J. Hered. 55:195-199.

Nemchenko, A., Kunze, S., Feussner, I., and Kolomiets, M. 2006. Duplicate maize 13-lipoxygenase genes are differentially regulated by circadian rhythm, cold stress, wounding, pathogen infection, and hormonal treatments. J. Exp. Bot. 57:3767-3779.

Nimchuk, Z., Eulgem, T., Holt, B. F., 3rd, and Dangl, J. L. 2003. Recognition and response in the plant immune system. Annu. Rev. Genet. 37:579-609.

Panter, S. N., and Jones, D. A. 2002. Age-related resistance to plant pathogens. Adv. Bot. Res. 38:251-280.

Panter, S. N., Hammond-Kosack, K. E., Harrison, K., Jones, J. D., and Jones, D. A. 2002. Developmental control of promoter activity is not responsible for mature onset of $C f-9 B$-mediated resistance to leaf mold in tomato. Mol. Plant-Microbe Interact. 15:1099-1107.

Parniske, M., Hammond-Kosack, K. E., Golstein, C., Thomas, C. M., Jones, D. A., Harrison, K., Wulff, B. B., and Jones, J. D. 1997. Novel disease resistance specificities result from sequence exchange between tandemly repeated genes at the $C f-4 / 9$ locus of tomato. Cell 91:821832.

Settles, A. M., Latshaw, S., and McCarty, D. R. 2004. Molecular analysis of high-copy insertion sites in maize. Nucleic Acids Res. 32:e54.

Song, W. Y., Wang, G. L., Chen, L. L., Kim, H. S., Pi, L. Y., Holsten, T., Gardner, J., Wang, B., Zhai, W. X., Zhu, L. H., Fauquet, C., and Ronald, P. 1995. A receptor kinase-like protein encoded by the rice disease resistance gene, Xa21. Science 270:1804-1806.

Staskawicz, B. J. 2001. Genetics of plant-pathogen interactions specifying plant disease resistance. Plant Physiol. 125:73-76.

Tiffin, P., Hacker, R., and Gaut, B. S. 2004. Population genetic evidence for rapid changes in intraspecific diversity and allelic cycling of a specialist defense gene in Zea. Genetics 168:425-434.

Ullstrup, A. 1941. Two physiologic races of Helminthosporium maydis in the corn belt. Phytopathology 31:508-521.

Walton, J. D. 1996. Host-selective toxins: Agents of compatibility. Plant Cell 8:1723-1733.

Whalen, M. C. 2005. Host defence in a developmental context. Mol. Plant Pathol. 6:347-360.

White, S., and Doebley, J. 1998. Of genes and genomes and the origin of maize. Trends Genet. 14:327-332.

Wolpert, T. J., Dunkle, L. D., and Ciuffetti, L. M. 2002. Host-selective toxins and avirulence determinants: What's in a name? Annu. Rev. Phytopathol. 40:251-285.

Zhang, L., Peek, A. S., Dunams, D., and Gaut, B. S. 2002. Population genetics of duplicated disease-defense genes, $h m 1$ and $h m 2$, in maize (Zea mays ssp. mays L.) and its wild ancestor (Zea mays ssp. parviglumis). Genetics 162:851-860. 